\title{
My morning glory
}

\author{
What a way to start the day.
}

\begin{abstract}
David Marusek
When I rise in the morning, I can hardly wait to run out to the living room and shout: “My Morning Glory! My Morning Glory!" Then My Morning Glory spins up and says, "Good morning, sir! You're out of bed early today - well ahead of schedule. We're off to a brilliant start on a brand new day!

This is my first kudo of the day. I pump my arm in the air and shout: "Yes!" On the media shelf, My Kudo Kounter is blinking: Keep up the good work! Then My Personal Trainer says: "Today is Tuesday, and we all know what Tuesday is - Nimble Knees Day!" So I place my hands on my knees and - slowly at first
\end{abstract} - rotate them clockwise, then

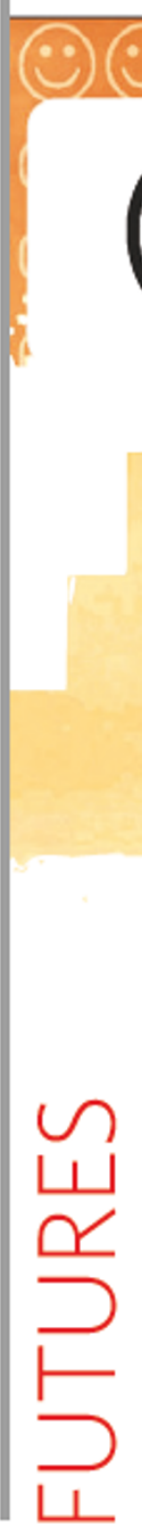

faster and faster until My Personal Trainer says "Reverse direction!" and I wobble to a halt and start rotating the other way.

Meanwhile, My Channel is downloading the headlines. The economy is looking up, and consumer confidence is high. We and Our Coalition Forces are winning all the wars. Global disasters during the past 24 hours: 0.

"Breakfast is served!" sings My Kitchen. Oatmeal with raisins, coffee with creamer, and a big smile of cantaloupe - yum! My Morning Glory says: ${ }^{\alpha}$ Time check - we've got time to burn!" So, I enjoy a second coffee and take an extended shower. As I shave, My Mirror scrolls text messages - Looking good there, champ and Did we lose a few pounds? My Closet picks out a dark suit and says, "A striped tie would be perfect for our afternoon HR meeting."

HR meeting? Suddenly, my guts clench up like a fist. I check My Calendar, and sure enough, My Annual Evaluation is today. This afternoon! Somehow I had managed to forget all about it. On the dresser, My Frown Jar says, "Uh-oh, someone owes me a dollar."

"Shut up!" I shout at it. "Shut up! Shut up, all of you!" I drop the clothes on the floor and collapse on the bed. This will be my first performance review since the merger announcement last

“That's good news, indeed. Time check — we're running late."

I sigh and get off the bed, finish dressing, and gather up My Things. "Goodbye," I say as I dimb into the airlock.

"Farewell, sir," My Morning Glory replies. ${ }^{\circ}$ Have a spectacular day and remember, My Happy Hour will be right here waiting for you when you return." I lock the inner hatch, and as the air is being exchanged, I strap on My Filter Mask and wait in front of the door. But when the door slides open, I simply can't force myself to egress. Tears well up in my eyes.

"Is there something else, sir?" My Morning Glory says.

"They're going to fire me. I know it."

In a little while, when still I don't move, My Morning Glory says, “Don't worry, sir. You're a survivor. You're a top performer. You're practically a Force of Nature. You'll do just fine."

${ }^{\alpha}$ But I don't feel like a Force of Nature. What if I don't measure up? I can't do this. I want to stay home."

My Morning Glory tuts and says, "Tell me, what's the Third Rule on the Road to Success?"

${ }^{\alpha}$ Third Rule? Baby steps. One step at a time."

"Exactly! And what is your next step? The HR meeting this afternoon, or something earlier? ${ }^{\text {" }}$

I check My Calendar. "I don't have anything earlier."

${ }^{\alpha} \mathrm{Oh}, \mathrm{no}$ ? What happens at ten o'dock?"

"That's My Morning Coffee Break."

"You are correct, sir!

My Morning Coffee Break, of course. At ten I take My Morning Coffee Break, which I love almost as much as My Morning Glory.

${ }^{\circ}$ Forget all about this afternoon, sir, and

quarter, and I'm not ready for it. My numbers are down; my management confidence is low.

My Apartment grows silent as all its tiny motors spin down. The room is so quiet I can hear the groan of the city through the wall. Finally, My Morning Glory says, "Is everything all right?"

${ }^{\alpha}$ No! Everything is not all right. Everything is a freaking disaster. I'm as good as dead."

"In that case, don't move. I'm calling an ambulance"

“Ambulance?" I say, sitting up. "I don't need an ambulance." focus on making it 'til ten. That's all you have to do. Now get out of here and show them what you're made of."

The moment I step across the threshold, the door slams and bolts behind me. I lift My Filter Mask to wipe my eyes. Then I straighten up and march resolutely into My Future.

Thank you, My Morning Glory.

I'd be lost without you.

When not working on his second novel, Mind over Oship, Alaskan author David Marusek is training his cabin to fetch him his slippers.

His debut novel, Counting Heads, was

released by Tor Books in November 2005. 